\title{
Adolescents as agents of healthful change through scientific literacy development: A school-university partnership program in New Zealand
}

Jacquie L. Bay ${ }^{1,4^{*}}$, Mark H. Vickers ${ }^{1}$, Helen A. Mora ${ }^{1}$, Deborah M. Sloboda ${ }^{1,2}$ and Susan M. Morton ${ }^{1,3}$

\begin{abstract}
Background: Scientific literacy development is widely emphasized as the overarching goal of science education. It encompasses development of understanding of the nature of science as well as knowledge, attitudes, and values that contribute to empowering adolescents to engage with and make evidence-based decisions about socioscientific issues. Scientific literacy development is enhanced when learning is contextualized in exploration of socioscientific issues.

Noncommunicable diseases (NCDs) associated with a combination of obesity and adverse environmental exposures are examples of pressing health-related SSIs facing the world today. Evidence emerging from the field of Developmental Origins of Health and Disease (DOHaD) has identified adolescence as a key life-phase where population-wide education-based interventions that empower teens to engage in science-based health-promoting behaviors could significantly change the course of this epidemic. To achieve this, learning resources that support scientific and health literacy development contextualized in issues linking NCD risk and DOHaD are required. The Healthy Start to Life Education for Adolescents Project is a school-university partnership program designed to support scientific and health literacy development, knowledge translation, and participant-led actions relating to NCD risk prevention. This study assesses the impact of program participation in a cohort of 11-14-year-olds in New Zealand. Evaluation comprised analysis of individually matched questionnaires, pre-, 3 months, and 12 months postintervention ( $n=201)$ and 6 months post-intervention interviews $(n=40)$.

Results: Positive engagement in science learning occurred. Positive changes in health-related awareness and attitudes 3 months post-intervention were sustained to 12 months. Adolescents reporting pre-intervention dietary behaviors associated with increased obesity risk reported sustained positive behavior changes $(p<.001)$. Qualitative evidence revealed that these changes resulted from application of scientific and health literacy. This has the potential to improve long-term health outcomes for adolescents and their future offspring. Furthermore, feedback from parents demonstrated that adolescents became science communicators within their families.

Conclusions: We demonstrated that contextualized learning promoting scientific and health literacy development facilitated knowledge translation. This allowed adolescents to decide if, and how, to use scientific evidence in relation to their current and future wellbeing. Exploration of the transferability of scientific and health literacy capabilities, and impacts on future health would enhance understanding of the value of the intervention.
\end{abstract}

\footnotetext{
*Correspondence: j.bay@auckland.ac.nz

'Liggins Institute and Gravida, National Centre for Growth and Development,

University of Auckland, Auckland, New Zealand

${ }^{4}$ Liggins Institute, University of Auckland, Private Bag 92109, Victoria Street

West, Auckland 1142, New Zealand

Full list of author information is available at the end of the article
} 


\section{Background}

The development of scientific literacy is a key goal of science education (Hodson 2011), contributing to the capabilities required for engaged citizenship. Scientific literacy enables the use of science knowledge in decision-making relating to everyday occurrences as well as complex open-ended socioscientific issues. Understanding of the epistemology of science as a way of knowing, (the nature of science), is central to scientific literacy. However, knowledge and understanding of relevant scientific concepts is also required, alongside competencies associated with critical thinking, problem solving, communicating, acting autonomously (Rychen and Salganik 2003), and attending to moral and ethical ramifications (Sadler et al. 2004).

Development of scientific literacy and associated competencies is enhanced when learning is contextualized in real-world issues (Hipkins et al. 2014). The noncommunicable disease (NCD) epidemic is one such issue. Considered one of the most pressing socioscientific issues of our time, NCDs are responsible for considerable and growing social and economic burden (Bloom et al. 2011). Dominated by overweight, obesity, cardiovascular disease, cancers, and type 2 diabetes mellitus, these slow developing chronic conditions account for $64 \%$ of deaths globally. The burden of long-term morbidity and premature death associated with NCDs is disproportionately high in populations with limited resources (WHO 2015). NCD risk is impacted by a matrix of biological and socioecological factors that create rich contexts for learning associated with the development of scientific literacy (Bay et al. 2016). Because the NCD epidemic is a health-related socioscientific issue learning, using this context to facilitate scientific literacy development should also support health literacy development (Grace and Bay 2011). Similar to scientific literacy, health literacy enables the use of evidence in health-related decision-making (Nutbeam 2008).

Increasing understanding of the complexity of overweight, obesity, and NCD vulnerability has led to calls for multi-sectoral approaches to NCD risk reduction (Chestnov et al. 2013). These include prevention strategies prior to the onset of risk, known as primary prevention. Such strategies are informed by evidence from the field of Developmental Origins of Health and Disease $(\mathrm{DOHaD})$ demonstrating that early life exposures, even before birth, as well as health status and nutritional exposures of either parent prior to conception, influence the vulnerability of an individual to later life obesity and NCDs (Hanson and Gluckman 2014).

Adolescence, a life stage where cognitive and lifestyle behaviors that track into adulthood are established, (Craigie et al. 2011; Steinberg 2005) offers significant opportunity for primary NCD risk prevention for the adolescent and their potential future offspring (Todd et al. 2015). Overweight and obesity in adolescence is known to persist into adulthood and impact future health (Alberga et al. 2012). Even if adolescence is significantly distanced from pregnancy, adolescent behaviors that track into adulthood will influence nutrition in the periconceptional period and during pregnancy, consequently influencing offspring vulnerability to obesity and related NCDs in later life (Bay et al. 2016). Thus, establishing positive nutritional and related lifestyle behaviors in the teenage years offers significant long-term health and social benefits for adolescents and their future offspring.

Life-long behaviors that develop during adolescence are influenced by educational, biological, cognitive, and socioecological factors. Therefore, the World Health Organization recognizes schools as having a key role in enabling primary NCD risk reduction (WHO 2016). However, school-based health interventions often have not been particularly successful (Khambalia et al. 2012) due to lack of connection to the core mission of schools (Waters et al. 2011). We have argued that this could be resolved by ensuring that school-based interventions are designed by educators working in partnership with health/science communities, integrate educational and health goals, utilize opportunities within existing curriculum objectives, are adaptable to enable differentiation, and involve educational as well as health-based evaluation (Bay et al. 2017; Bay and Vickers 2016). Science is a key learning area where opportunities for contextual learning supportive of scientific and health literacy development and primary NCD risk reduction exist. Such learning can offer adolescents the potential to apply scientific perspectives to decision-making that will influence their future NCD risk, as well as assisting them to understand the complexity of the NCD epidemic as a significant global issue.

New Zealand has a devolved curriculum centered on key competencies developed across all learning areas. In a devolved curriculum, high-level achievement aims grouped by strands are defined for each learning area. The responsibility of defining specific learning objectives and contexts within which learning will be set is devolved to the school. In science, the core strand, "Nature of Science," is divided into four themes: understanding about science, investigating in science, communicating in science, and participating and contributing (bringing a scientific perspective to actions). Contextual strands (living-world, physical-world, material-world, and planet earth and beyond) support achievement aims defined in the Nature of Science strand alongside aims associated with understanding of scientific concepts (MoE 2007).

Representative of many settings, New Zealand is experiencing increasing overweight and obesity in children 
and adolescents as well as in adults (MOH 2012; Rajput et al. 2015; Utter et al. 2015). Considered together with information on the decreasing age of onset of type 2 diabetes mellitus in youth (Jefferies et al. 2012) and the increasing rates of pre-diabetes and diabetes in adults (Coppell et al. 2013), these data signal a growing future NCD burden for New Zealand. Thus, the NCD epidemic offers a highly relevant learning context for schools.

The Healthy Start to Life Education for Adolescents Project (HSLEAP) is a multi-sectoral Science Education Partnership involving the Liggins Institute and schools ("LENScience Healthy Start to Life," n.d.). Based on our "science for health literacy" pedagogical model (Grace and Bay 2011) programs facilitate learning that supports the development of capabilities associated with scientific and health literacies through exploration of aspects of the NCD epidemic. Programs are based on a narrative pedagogy, meaning that learning is facilitated by the exploration of stories associated with the socioscientific issue being considered. These stories include evidence from the community, health, and science. They enable adolescents to examine the relevance of the issue to their community, and the potential of primary NCD risk reduction to support improved long-term health and wellbeing. Programs support Nature of Science learning objectives at levels 4 and 5 of the New Zealand Curriculum, Fig. 1, ensuring validity for schools.
This study aimed to assess the potential of HSLEAP programs undertaken in year 7-10 (age 11-14 years) science classrooms in New Zealand to contribute towards development of science and health literacies, and simultaneously empower adolescents to engage in evidencebased decision-making in relation to lifestyle factors associated with nutrition. We have shown previously that exposure of year 7-10 students in New Zealand to HSLEAP programs stimulated evidence-based decisionmaking related to health-promoting behaviors at 3 months post-intervention (Bay et al. 2012a). This paper reports on educational and health-related impacts of this program exposure 12 months post-intervention.

\section{Methods}

The study utilized a mixed methods approach within an individually matched repeated time-series design (Biglan et al. 2000), Fig. 2, approved by the University of Auckland Human Participants Ethics Committee (ref. 2009/426).

Analyzing individual change is important within community-based interventions as impacts will vary dependent on participant circumstances (Biglan et al. 2000). To achieve this, student questionnaire data was collected at baseline (pre-intervention) (T0), 3 months, (T2) and 12 months post-intervention (T4) and matched for each individual to assess the

\begin{tabular}{|c|c|c|}
\hline Nature of Science & Curriculum Level 4 (Years 7-9) & Curriculum Level 5 (Years 9-10) \\
\hline $\begin{array}{l}\text { Understanding } \\
\text { about Science }\end{array}$ & $\begin{array}{l}\text { Appreciate that science is a way of } \\
\text { explaining the world and that science } \\
\text { knowledge changes over time. } \\
\text { Identify ways in which scientists work } \\
\text { together and provide evidence to } \\
\text { support their ideas. }\end{array}$ & $\begin{array}{l}\text { Understand that scientists' } \\
\text { investigations are informed by current } \\
\text { scientific theories and aim to collect } \\
\text { evidence that will be interpreted } \\
\text { through processes of logical argument. }\end{array}$ \\
\hline $\begin{array}{l}\text { Investigating in } \\
\text { science }\end{array}$ & $\begin{array}{l}\text { Build on prior experiences, working } \\
\text { together to share and examine their } \\
\text { own and others' knowledge. } \\
\text { Ask questions, find evidence, } \\
\text { explore simple models, and carry out } \\
\text { appropriate investigations to develop } \\
\text { simple explanations. }\end{array}$ & $\begin{array}{l}\text { Develop and carry out more complex } \\
\text { investigations, including using models. } \\
\text { Show an increasing awareness of the } \\
\text { complexity of working scientifically, } \\
\text { including recognition of multiple } \\
\text { variables. } \\
\text { Begin to evaluate the suitability of the } \\
\text { investigative methods chosen. }\end{array}$ \\
\hline $\begin{array}{l}\text { Communicating in } \\
\text { science }\end{array}$ & $\begin{array}{l}\text { Begin to use a range of scientific } \\
\text { symbols, conventions, and vocabulary. } \\
\text { Engage with a range of science texts } \\
\text { and begin to question the purposes for } \\
\text { which these texts are constructed. }\end{array}$ & $\begin{array}{l}\text { Use a wider range of science } \\
\text { vocabulary, symbols, and conventions. } \\
\text { Apply their understandings of science } \\
\text { to evaluate both popular and scientific } \\
\text { texts (including visual and numerical } \\
\text { literacy). }\end{array}$ \\
\hline $\begin{array}{l}\text { Participating and } \\
\text { contributing }\end{array}$ & $\begin{array}{l}\text { Use their growing science knowledge } \\
\text { when considering issues of concern to } \\
\text { them. } \\
\text { Explore various aspects of an issue and } \\
\text { make decisions about possible actions. }\end{array}$ & $\begin{array}{l}\text { Develop an understanding of socio- } \\
\text { scientific issues by gathering relevant } \\
\text { scientific information in order to draw } \\
\text { evidence-based conclusions and to take } \\
\text { action where appropriate. }\end{array}$ \\
\hline
\end{tabular}

Fig. 1 New Zealand Curriculum, Nature of Science Learning Objectives, levels 4 and 5 (MoE 2007) 


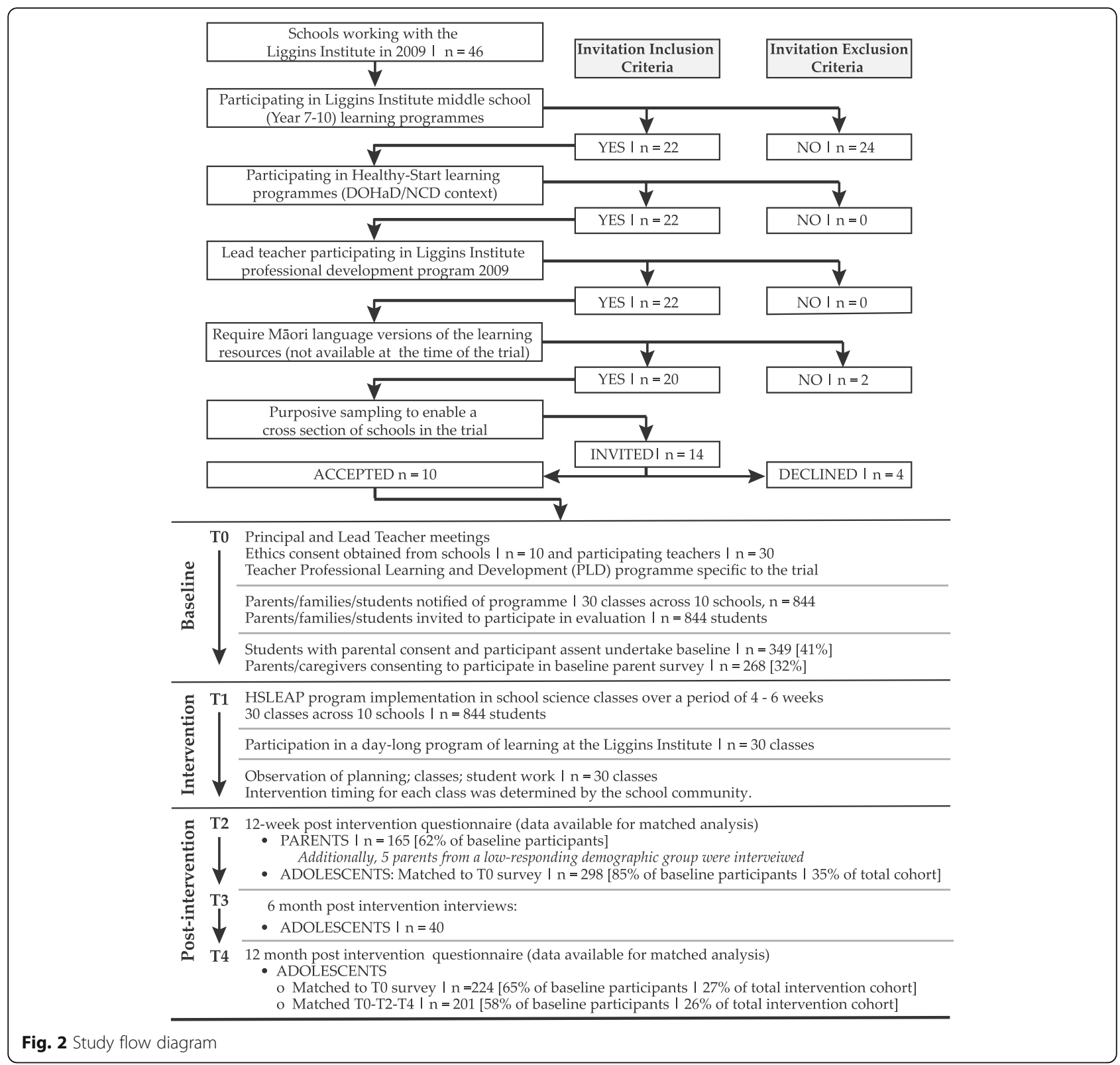

potential for program participation to support scientific and health literacy development, and for this to impact health and science-related knowledge, attitudes, and behaviors. Parent questionnaire data was collected and matched at T0 and T2. Matching of individual participant data enabled reporting of cohort-wide knowledge, attitude, and behavior trends at time-points, and change patterns based on aggregation of individual differences between time-points. Use of an explanatory mixed methods design (Punch 2009) enabled examination of the potential of qualitative data to corroborate quantitative data (Bryman 2008) and contributed evidence relating to why change did or did not occur.

\section{Context}

The study was conducted in 30 classrooms ranging from years 7-10 across 10 Auckland schools. In New Zealand, curriculum levels span year levels. Curriculum levels 4 and 5 span years $7-10$. Teachers design learning programs that enable students to progress through appropriate curriculum levels in mixed-ability classrooms. Hence, the diversity of year levels and schools in the study is appropriate and contributes towards addressing issues related to the impact of heterogeneity and complexity in school settings. Participating schools elected when to undertake the study to ensure integration into their science learning programs. The resulting data collection period spanned from 2010 to 2013. 


\section{Recruitment}

Schools were selected from a group of 46 participating in the Liggins Institute's school partnership programs in 2009 (Bay et al. 2012b ). Inclusion criteria described in Fig. 2 generated a sample of 20 schools. Using purposive sampling, 13 schools were invited, aiming to create a sample representative of schools in the region. Prior to formal consent being sought, meetings occurred between invited schools and the Institute to discuss the study, intervention tool development, and research methods and to confirm appropriate recruitment processes. Nine schools accepted the invitation to participate, three of which were single-sex girls' schools. On completion of the pre-intervention data collection a combination of two single-sex girls' schools with high rates of participation and three co-educational schools from the lowest socioeconomic setting (SES) with low rates of participation had created a significant gender imbalance. To address this, a single-sex boys' school was added to the study. Published evidence at 6 months post-intervention included nine schools (Bay et al. 2012a). Impacts to 12 months post-intervention reported here are from all ten schools.

Consent/assent to participate was obtained from principals, teachers, parents, and students. Meetings were held with all involved teachers and classes prior to written information being provided to families. Depending on school policy and practice, information about the study was also provided to families via school newsletters or parent meetings. Irrespective of participation in evaluation, all students were exposed to HSLEAP learning modules. Learning resources and teacher professional development were provided for each school.

\section{Intervention tools}

Intervention tools were developed by a multi-sectoral team led by science educators working as "intermediaries" (Bolstad and Bull 2013) capable of crossing science, education, and health. Tools consisted of adaptable learning modules based on the HSLEAP learning and teaching framework (Fig. 3) and contextualized in exploration of aspects of the NCD epidemic (Bay and Mora 2009a; Bay and Mora 2009b). The contexts were (a) nutrition (including early life) and later life obesity and cardiovascular disease vulnerability or (b) early life nutrition, early puberty and later life obesity, and NCD risk. Opportunities for students to explore scientific evidence are central to the framework. This is achieved via learning resources that use stories to enable students to explore the work of scientists and examine scientific evidence that is presented in formats that enable ageappropriate access (Bay et al 2012c). This enables students to traverse into the culture of science, encounter scientists, their stories, and scientific evidence and

\section{Explore the context/socio-scientific issue}

Learning experiences support exploration:

- What do I know about ...?

- How does ... impact me, my family, my community, my country, the world?

- Making frames of reference visible:

- How do I view this issue?

- How do other people view this issue?

- What does research tell us about this issue?

- What would I like to know?

- What possible actions could be taken in society, my community, my school, my family?
Develop capabilities (knowledge, attitudes, skills and values)

Learning experiences support development of capabilities required to engage in exploration of the context/SSI:

- Knowledge of \& about science, health \&society;

- Attitudes towards science, health \& society;

- Competencies (e.g. the ability to interpret, evaluate, explain, consider differing viewpoints, jointly consider values, culture and research in evidence-based decision-making, deal with uncertainty).

\section{Inquire/investigate and make decisions}

Learning experiences support students to:

- Take responsibility for inquiry into a specific question;

- Use evidence to make decisions about actions that they, their family, or their community may take in response to the issue;

- At senior levels (ages 15+), consider \& propose potential government, regional, globa actions relating to the issue.

\section{Communicate}

Learning experiences support students to communicate with their family, peers and their community about:

- Learning they have undertaken;

- Findings of their inquiry;

- Actions that they would like to take, have taken, believe could make an impact at a particular level (family, community, society). 
explore similarities and differences between scientists' ideas and ways of thinking and their own. Combined with experiences of NCDs from families and/or communities, these narratives enable adolescents to construct and potentially act upon contextual understanding of evidence relating to life course approaches to NCD risk reduction. Each school developed a 4-6 weeks learning module (1218 classroom hours) based on the framework and appropriate for their setting. During the module classes were exposed to "LENScience Face-to-Face," a 1-day hands-on learning program exploring $\mathrm{DOHaD}$ research evidence at the Liggins Institute ("LENScience Face-to-Face," n.d.).

\section{Data collection}

Data sources included questionnaires, interviews, observations, and review meetings. Questionnaires for students, enabling quantitative analysis of knowledge, attitudes, and behaviors, utilized Likert attitude scales and closed items, and for parents in addition included open items (Additional file 1). Paper-based student questionnaires were completed in class under the guidance of a teacher who ensured students understood the nature of the questions and could seek clarification. Each school determined the format of the parent questionnaire. This was paper-based in nine schools and online via an email invitation in one school. Student interviews were conducted within the school environment by science educators within the research team who were not teaching the students (Additional file 1). Semistructured open-ended questions were used. As reported previously (Bay et al. 2012a), difficulty in recruiting parents from schools in a low-socioeconomic demographic was addressed via interviews with five parents from this demographic. These semi-structured interviews, conducted by science educators from the research team, drew on the questions asked in the parent questionnaire. Review meetings with teachers and classroom observations confirmed that delivery of the intervention module was representative of the HSLEAP framework and sought feedback on student responses and potential improvements to the program.

\section{Data analysis}

Publically available school demographic data (MoE 2012) provided information on the range of communities represented within the study. Quantitative data was analyzed using SPSS, (IBM Corp 2015). Descriptive statistics were used to identify frequencies. Comparison of response frequencies between groups was evaluated with Chi-square, Fisher's exact and Mann-Whitney $U$ tests as appropriate. Distribution of responses of self-matched ordinal data at pre-intervention. 3-, and 12 months postintervention was analyzed using the Friedman test followed by post hoc assessment using the Wilcoxon
Signed-Rank test. Matched binomial data were analyzed using Cochran's $Q$ test. Ordinal logistic regression was used to ascertain the effects of gender on cohort-wide response patterns. Bonferroni-Holm's correction for multiple comparisons was applied (Aickin and Gensler 1996). Interviews were transcribed and anonymized prior to theme sorting using a constant comparative approach and inductive coding (Boyatzis 1998) in line with the relativist ontological and subjective epistemological approach (Levers 2013). Coding was conducted independently by two researchers and checked for inter-observer variability. Qualitative responses from parent questionnaires were treated similarly.

\section{Participants}

Table 1 describes demographic characteristics and response rates for students. The students who participated in evaluation $(n=349)$ may not be representative of the intervention cohort $(n=844)$. Without access to school records, this could not be assessed. However, comparison of baseline data for those who did or did not complete all questionnaires demonstrated that the students who completed all questionnaires had a similar demographic and baseline response profile to those who responded to T0 and/or T0-T2 only Additional file 2. Where differences were found, the T0-T2-T4 matched group demonstrate attitudes and behaviors that are slightly less health-aware than the T0 and/or T0-T2 group. Parental evidence was received from $32 \%$ of the cohort at baseline with matched T0-T2 data available from 165 parents (Fig. 2), more than $50 \%$ of whom were linked to schools in the highest SES category.

The schools, nine of which were described in detail in Bay et al. 2012a, represented a cross section of communities from low to high SES. For New Zealand schools, this categorization is based on the SES of families within a school's catchment area, calculated from census data relating to household income, educational qualifications, and occupation of adults within the household, household crowding, and income support provided to the household. Decile 10 includes the $10 \%$ of schools with the lowest proportion of low SES families within the catchment. Decile 1 includes the $10 \%$ of schools with the highest proportion of low SES families within the catchment (Ministry of Education 2017). We reported in Bay et al. 2012a that parents from schools in the lowest SES category (decile 1-4) were least likely to consent to students participating in the study. Discussion with teachers and parents suggested that this was associated with the requirement for written consent. Evaluation retention of students from this group was 1.2-fold greater than overall retention rates Table 1 . However, at only $20 \%$ of the total cohort, this was inadequate to enable analysis of SES impacts on program response. Despite 


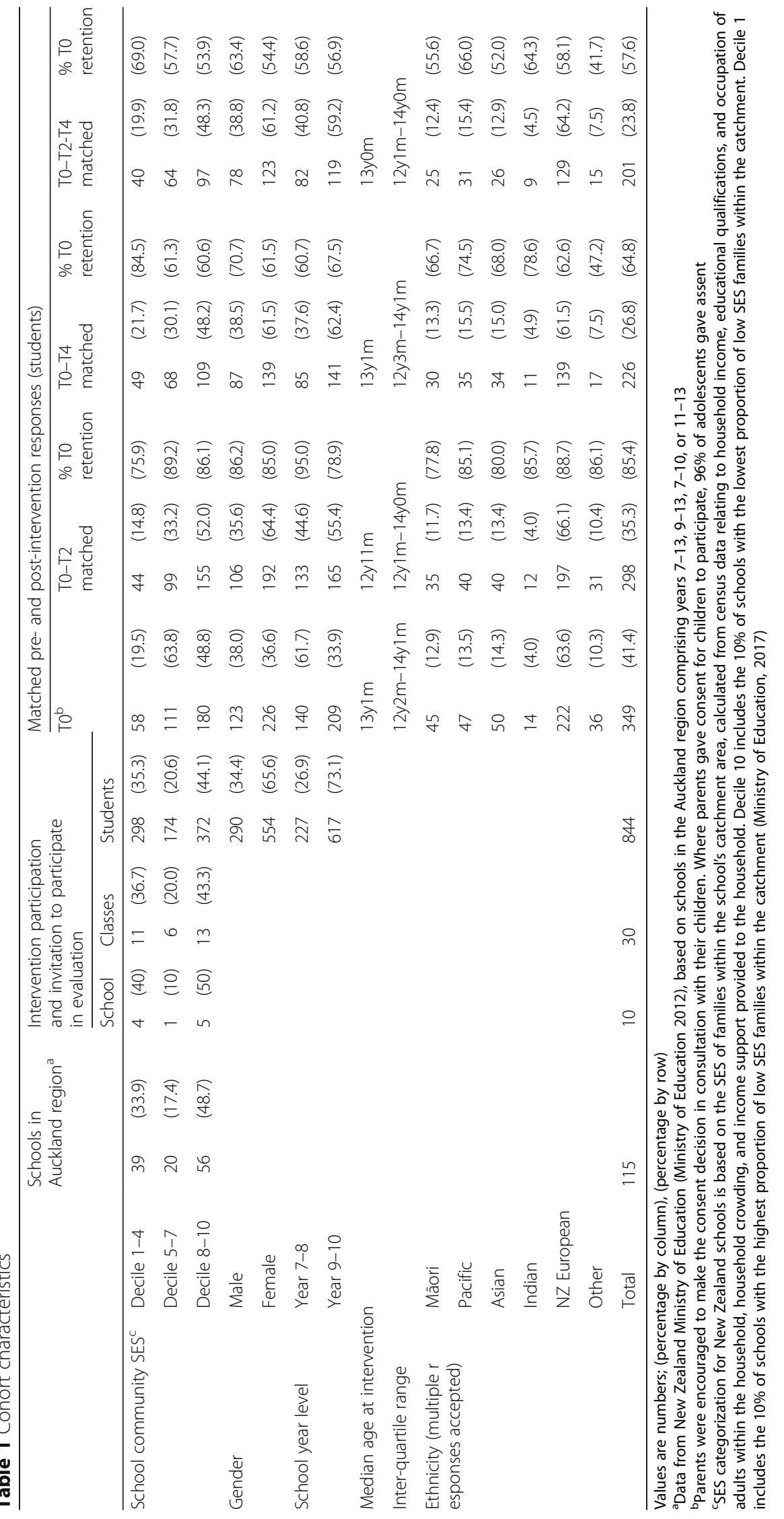


the female bias in the cohort noted earlier as a limitation of the study, T0-T2-T4 matched sample was $38 \%$ male, enabling limited evaluation of the impact of gender on program response.

\section{Results}

If sustained actions are to emerge from program participation, it should be possible to identify behavioral and emotional engagement during and beyond the intervention period.

Teachers from diverse settings identified positive behavioral engagement during the intervention.

"I have observed full engagement from students who often opt out." Teacher, decile 1-4.

"Students are seeing a different side of science. They are very positive about learning more about their health and wellbeing." Teacher, Decile 8-10

"It got the students working and engaged." Teacher, Decile 5-7

Emotional engagement was indicated by factors such as enjoyment, interest, and identification of relevance of the program to personal situations.

"It is all relevant. That enables the students to stay engaged." Teacher, Decile 8-10

"I am interested that they appear so receptive. Great to see the kids' enthusiasm in delivering their findings and information at the conference" Parent, Decile 810, T2 survey

"All the time he is talking about it. Before [the project] most of the time he didn't talk about school but since this project started he has really started talking about this - about Health, Science and PE. He has been going on the computer and he has done a lot of research. To be honest I am amazed he has stepped out of the school space and is doing work on his own at home. He is motivated." Parent, Decile 1-4; T2 interview

Further examples of emotional engagement were reported previously in Bay et al. 2012a. When behavioral and emotional engagement leads to cognitive engagement, the potential exists for development and application of capabilities resultant in actiontaking. To assess this, we looked at evidence relating to attitudes and understanding, followed by evidence associated with actions emerging from cognitive engagement.

\section{Awareness of and engagement with science}

Assessment of understanding of key elements of the nature of science associated with the development of scientific literacy is presented in Tables 2 and 3. Pre-intervention the cohort generally understood science as an activity that seeks to understand the natural world via observation and inquiry. Investigation of common misconceptions relating to nature of science understanding sought to understand whether these were evident pre-intervention, and if so, whether program participation was associated with altered understanding. The misconceptions investigated were lack of creativity in science and certainty of scientific knowledge (Lederman et al. 2013). At T0, 64.7\% of adolescents associated creativity and imagination with scientists. While overall cohort change was not significant, of the 69 students who responded Disagree (D), Strongly Disagree (SD), or Don't Know (DK) at T0, 45\% changed to a position of Agree (A) or Strongly Agree (SA) post-intervention and retained this to T4, $p<.001$. In contrast, only $18 \%$ of the 126 students who initially responded SA/A changed to an uncertain or negative position at T4.

At T0, over $50 \%$ of students disagreed with the statement "Science is always about being sure of the answer." Overall proportions of students taking this view did not alter significantly. However, $43 \%$ of the 75 students who pre-intervention responded SA/A moved to SD/D while only $22 \%$ of the 110 students who pre-intervention responded SD/D moved to SA/A. The odds of boys associating science with certainty was 2.6 times that of girls at T0, $p<.001$. At T2, this rose to 2.9 times that of girls, $p<.001$; while at T4, it reduced to 2.0 times that of girls, $p=.008$. These data should be of interest in boys' schools as they suggest that unless teachers actively provoke discussions, it may be less likely that this frame of reference will be challenged.

People are unlikely to engage with and use scientific knowledge in decision-making if they do not trust science. Public distrust of science is common. It is associated with the use of science in regulatory capacities (Engdahl and Lidskog 2014) and risk analysis (Retzbach et al. 2016). Asked if science could be trusted, $74 \%$ of students responded SA/A at T0, with a small significant shift towards SA at T4. Of the 149 students responding SA/A at T0, only $18 \%$ moved to a negative response by $\mathrm{T} 4$ whereas $57 \%$ of the 51 students responding DK/D/SD at T0 moved to SA/A at T4. No significant gender difference was seen at T0. By T2, the odds of boys agreeing that science could be trusted was 2.8 times that of girls, $p=.001$, dropping to 2.0 at T4, $p=.013$. The relatively high level of trust in science exhibited may be supportive of engagement in exploration of NCD risk. The gender difference post-intervention warrants further investigation. Combined with the gender difference regarding the tentative nature of evidence this should be a point of discussion for teacher planning. 
Table 2 Perceptions of science: matched pre-post responses showing cohort-wide and individual change trends, $n=201$

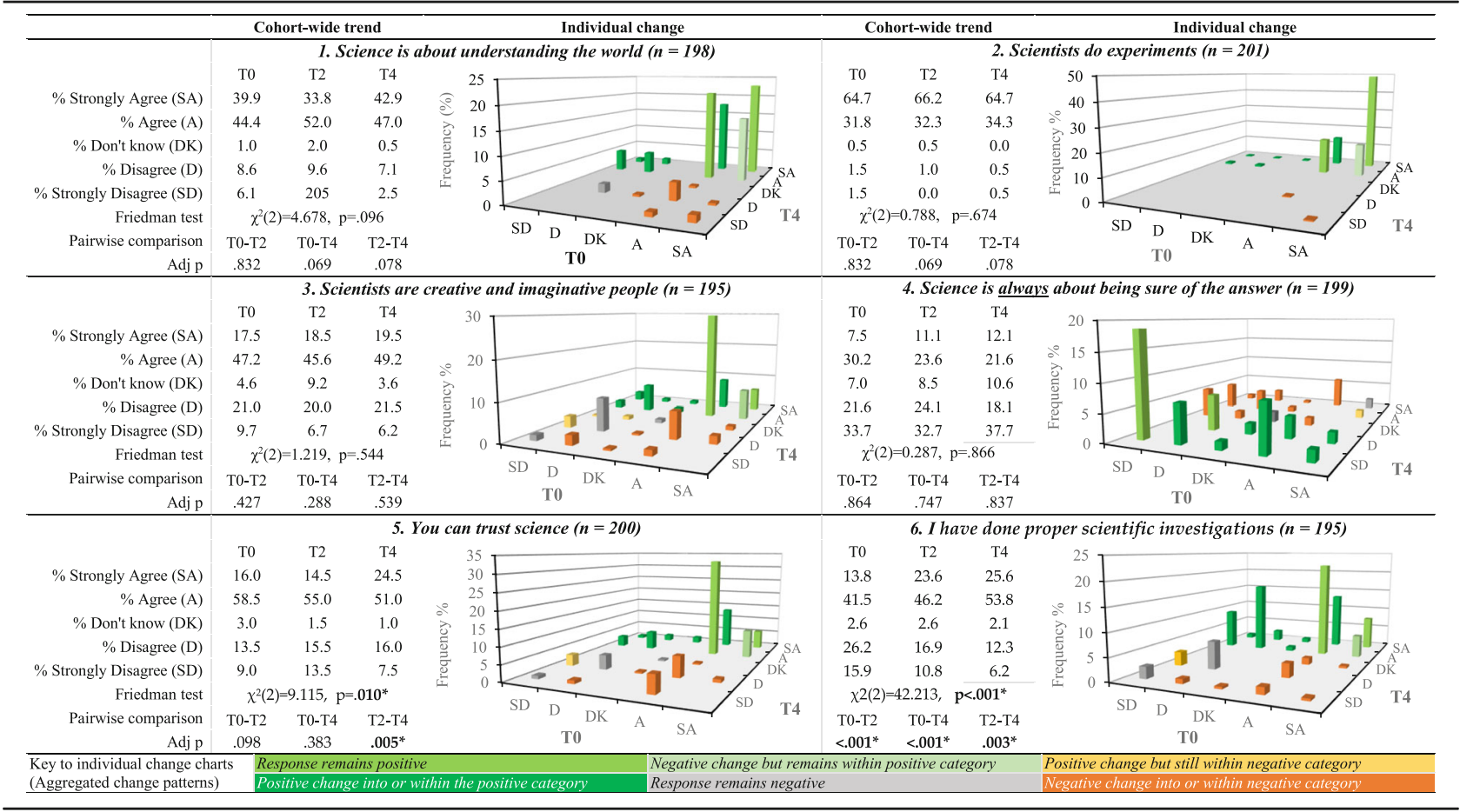

Variance in distribution of matched responses at T0, T2, and T4 was measured using the Friedman test. Post hoc pairwise comparisons were conducted using Wilcoxon Signed-Rank test

T0 pre-intervention, T2 6-12 weeks post-intervention, T4 12 months post-intervention, n number, Adj p adjusted significance values and include Bonferroni-Holm's correction for multiple comparisons

*Bold: significant $(a=0.05)$

Table 3 Perceptions of science: odds ratio $(95 \% \mathrm{Cl})$, male compared to female responses

\begin{tabular}{|c|c|c|c|c|c|}
\hline Statement & Time & OR (male cf. female) & $95 \% \mathrm{Cl}$ & $x^{2}(1)$ & p \\
\hline \multirow[t]{3}{*}{ 1. Science is about understanding the world } & T0 & 0.8 & $0.5-1.4$ & 0.493 & .483 \\
\hline & $\mathrm{T} 2$ & 1.7 & $1.0-2.9$ & 3.601 & .058 \\
\hline & T4 & 1.3 & $0.8-2.3$ & 0.901 & .342 \\
\hline \multirow[t]{3}{*}{ 2. Scientists do experiments } & T0 & 1.3 & $0.7-2.4$ & 0.817 & .366 \\
\hline & $\mathrm{T} 2$ & 1.4 & $0.7-2.5$ & 1.061 & .303 \\
\hline & T4 & 0.7 & $0.4-1.3$ & 1.106 & .293 \\
\hline \multirow[t]{3}{*}{ 3. Scientists are creative and imaginative people } & T0 & 1.9 & $1.1-3.3$ & 5.872 & $.015^{*}$ \\
\hline & $\mathrm{T} 2$ & 1.7 & $1.0-2.9$ & 4.133 & $.042^{*}$ \\
\hline & T4 & 2.4 & $1.4-4.2$ & 9.947 & $.002^{*}$ \\
\hline \multirow[t]{3}{*}{ 4. Science is always about being sure of the answer } & T0 & 2.6 & $1.6-4.5$ & 12.896 & $<.001^{*}$ \\
\hline & $\mathrm{T} 2$ & 3.0 & $1.7-5.0$ & 16.258 & $<.001^{*}$ \\
\hline & T4 & 2.0 & $1.2-3.4$ & 6.966 & $.008^{*}$ \\
\hline \multirow[t]{3}{*}{ 5. You can trust science } & T0 & 1.4 & $0.8-2.5$ & 1.571 & .210 \\
\hline & $\mathrm{T} 2$ & 2.8 & $1.6-4.9$ & 12.013 & $.001^{*}$ \\
\hline & T4 & 2.0 & $1.2-3.5$ & 6.165 & $.013^{*}$ \\
\hline \multirow[t]{3}{*}{ 6. I have done proper scientific investigation } & T0 & 1.4 & $0.8-2.4$ & 1.519 & .218 \\
\hline & $\mathrm{T} 2$ & 1.0 & $0.6-1.8$ & 0.025 & .875 \\
\hline & T4 & 1.8 & $1.0-3.1$ & 4.102 & $.043^{*}$ \\
\hline
\end{tabular}

The effect of gender on responses was measured using ordinal logistic regression with proportional odds

TO pre-intervention, T2 6-12 weeks post-intervention, T4 12 months post-intervention

*Significant $(a=0.05)$ 
Doing science is associated with contributing towards nature of science understanding when combined with explicit instruction and opportunities for reflection (Kahana and Tal 2014). At baseline, 13.8\%/41.5\% of students respond SA/A to the statement "I have done proper scientific investigations at school" At T2, this shifted to $23.6 \% / 46.2 \%$, rising slightly at $\mathrm{T} 4,25.5 \% /$ $53.8 \%, p<.001$. Contributors to this shift could include changes in understanding of the process of science, and thus, appreciation of prior experiences, changes in teaching practice reflected in student experience, or a combination of both. It is likely that most students had undertaken open-ended investigations prior to the intervention as this is a component of the New Zealand Curriculum. During the intervention, all classes experienced learning exploring the process of science and carried out some form of open investigation. This suggests that the use of science narratives within the intervention may increase understanding of what science is and allow students to recognize science more readily.

Meeting scientists (actually and through narratives) enables students to explore epistemologies that may be different to their own. This supports the potential for frames of reference to be adapted to include evidencebased scientific perspectives in addition to perspectives arising from personal contexts. The majority of adolescents had little or no contact with scientists outside of their school environment Fig. 4. Pre-intervention, 37\% of students identify with having met a scientist. Of this group, $63.5 \%$ identify either a teacher or a person they have met via a school event. Students did not identify all teachers as scientists. For example, in a school with six participating teachers, $39 \%$ of students identified having met a scientist at T0 and $68 \%$ of these qualified their answer by naming one or other of two teachers, both of whom had prior work experience in science. Postintervention, the proportion of students identifying as having met scientists increases to greater than $70 \%$, $p<.001$. While school-related encounters still dominate, there is a significant shift towards school events linked to the program. No significant differences were observed between the responses of boys and girls.

\section{Perceptions of the importance of health and lifestyle}

A comparison of matched pre-post responses to statements exploring perceptions of the importance of health

(a) Have you met a scientist?

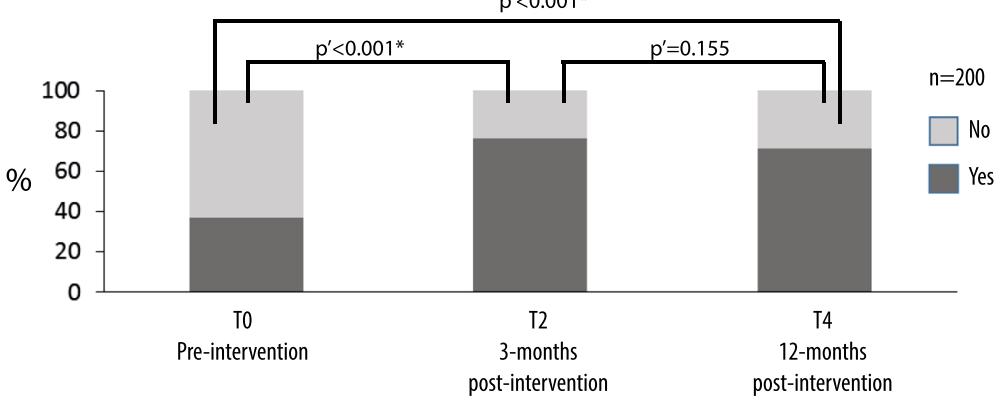

(b) If you have met a scientist, please say who it was or what kind of scientist they were. (Multiple answers were accepted)

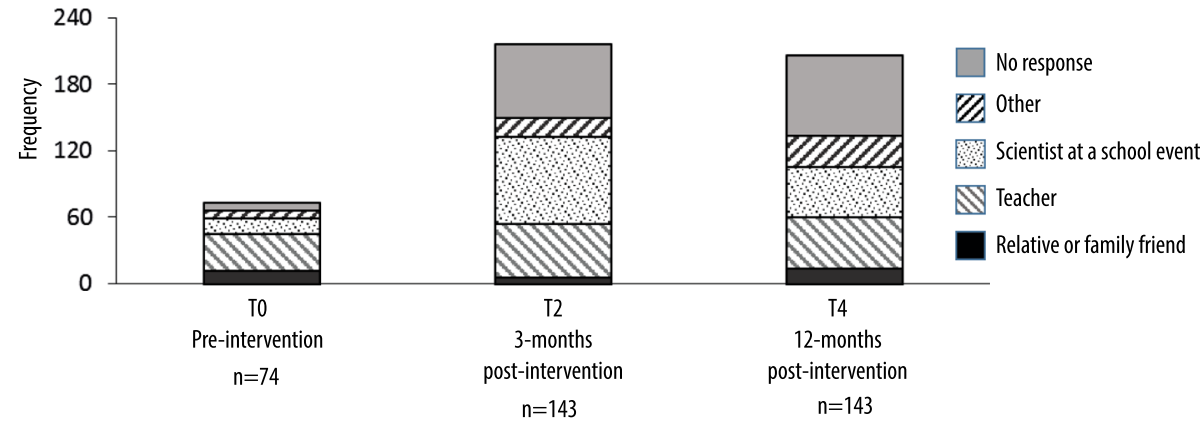

Fig. 4 Experiences of meeting scientists. Matched pre-post responses, $n=201$. a Matched pre-post responses to statement 7. Have you met a scientist? Variance in distribution of matched responses at T0, T2, and T4 was measured using the Cochran's $Q$ test, $Q=98.255, p<0.001$. Post hoc pairwise comparisons shown on the figure were conducted using McNemar's test. The Bonferroni-Holm's correction for multiple comparisons was applied. Binomial logistic regression demonstrated no significant difference between the responses of boys and girls. $\mathbf{b}$ Matched pre-post responses to statement 8 . If you have met a scientist, please say who it was or what kind of scientist they were? Variance in the frequency of responses in each category was measured using the Chi-Squared test, $X^{2}(8)=53.48,{ }^{*} p<.001$ 
and lifestyle was used to assess the impact of program participation on engagement with health as an issue of relevance to adolescents. Qualitative data at 6 months post-intervention demonstrated that students considered health as a concept that encapsulated physical, social, and emotional factors, and correctly interpreted concepts of healthy and unhealthy foods (Bay et al. 2012a). Pre-intervention students rated highly ("quite a lot" or "a lot") the importance of "being healthy" (94.5\%), "what you eat" (88.5\%) and "daily exercise" (87.9\%) Fig. 5. At baseline, students were less likely to rate "what you eat" as mattering "a lot" (39.0\%) compared to being healthy $(55.1 \%)$ and exercising daily (51.0\%), assessed via Cochran's $Q$ test to be significant $X^{2}(2)=18.143$, $p<.001$. Post hoc analysis revealed that the difference was between "what you eat" vs "being healthy," $p<.001$, and "what you eat" vs "daily exercise," $p=.006$. At 3 and 12 months post-intervention, there was a significant increase in students identifying "being healthy" $X^{2}(2)=9.297, p=.010$ and "what you eat" as mattering "a lot" $\chi^{2}(2)=6.889, p=.032$, suggesting that engagement was associated with positive attitudinal change. Conversely, there was no change in students' perceptions of the importance of daily physical activity, a concept not explored within the program.

\section{Awareness of associations between nutrition and health}

Responses to statements exploring awareness of associations between nutrition in early life and adolescence and health assessed the potential for the narrativebased exploration of $\mathrm{DOHaD}$ evidence within the learning program to support development of awareness of this evidence as a component of NCD vulnerability (Tables 4 and 5).

Pre-intervention SA/A responses to statement 12 "The food a woman eats when she is pregnant affects the health of her baby" were high (53.1/40.8\%). Significant positive shift towards SA occurred at T2 (62.8/35.7\%) and was sustained to $\mathrm{T} 4,(61.2 \% / 36.2 \%)$, suggesting that the program increased awareness of this concept, $p=.016$. Gender difference in T0 response indicating that boys were less likely than girls to respond positively $(p=.088)$ did not alter markedly post-intervention.

The concept of association between the nutritional environment of the mother during pregnancy and later life health (statement 13) elicited a wide range of preintervention responses. The odds of boys responding positively at T0 was 2.2 times that for girls $p=.003$. Strong positive change in awareness was observed at T2 and sustained to T4, $p<.001$. Of the $47.2 \%$ of participants who pre-intervention did not demonstrate awareness of this concept, $73.3 \%$ demonstrated awareness at 12 weeks post-intervention, $81.8 \%$ of whom continued to demonstrate this awareness at 12 months postintervention. Awareness in girls increased markedly between T0 and T2, with the odds of boys responding positively at T2 lowering to 1.3 compared to that of girls $p=.286$. Retention of SA/A response was higher in boys (92\%) compared to girls (83\%) at T4. Correspondingly, the odds of boys responding positively at $\mathrm{T} 4$ increased to 2.2 that of girls, $p=.004$.

The learning resources did not explore associations between paternal nutritional environment prior to conception and offspring health. However, this concept was attracting increasing attention within the $\mathrm{DOHaD}$ community at the time of the intervention ( $\mathrm{Ng}$ et al. 2010). It was raised as a question in teacher professional development, as well as by students in the one-day Liggins Institute program in the years prior to this intervention. Therefore, the concept was included as a point of emerging interest without exploration of evidence in the oneday Liggins Institute sessions attended by all participants.

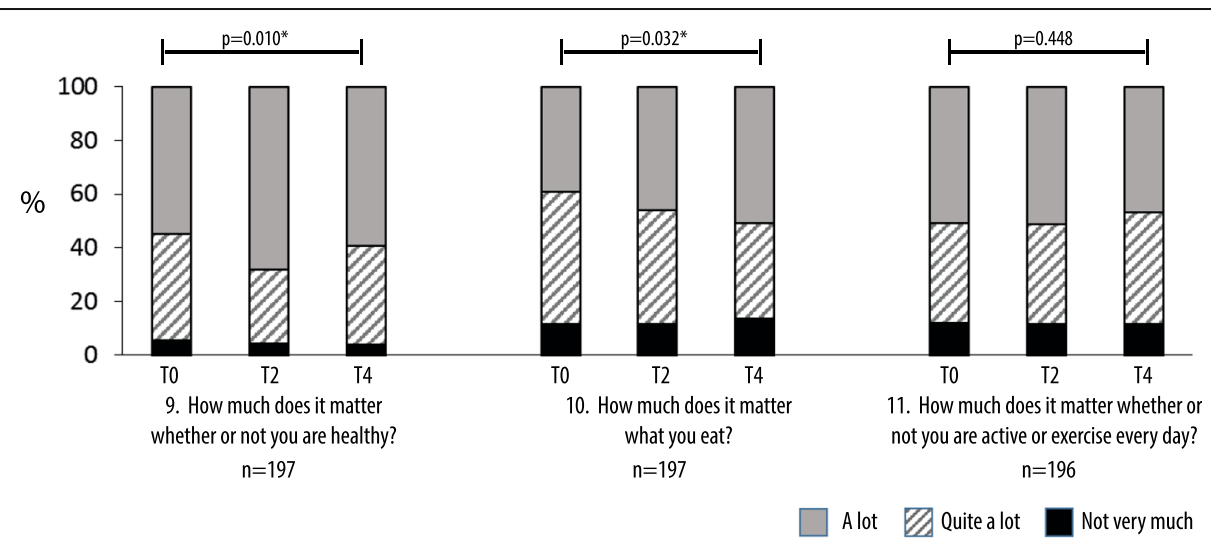

Fig. 5 The importance of health and lifestyle. Matched pre-post responses, $n=201$. Variance in proportion of responses confirming "a lot" vs less than "a lot" was assessed via related samples Cochran's $Q$ test, ${ }^{*}$ significant $(a=0.05)$. The effect of gender on responses was measured using a cumulative odds ordinal logistic regression with proportional odds. A significant difference in response based on gender was identified for statement 10 at T2 where the odds of boys identifying that what you eat mattered a lot was 0.4 times that of girls, $p=0.009$ 


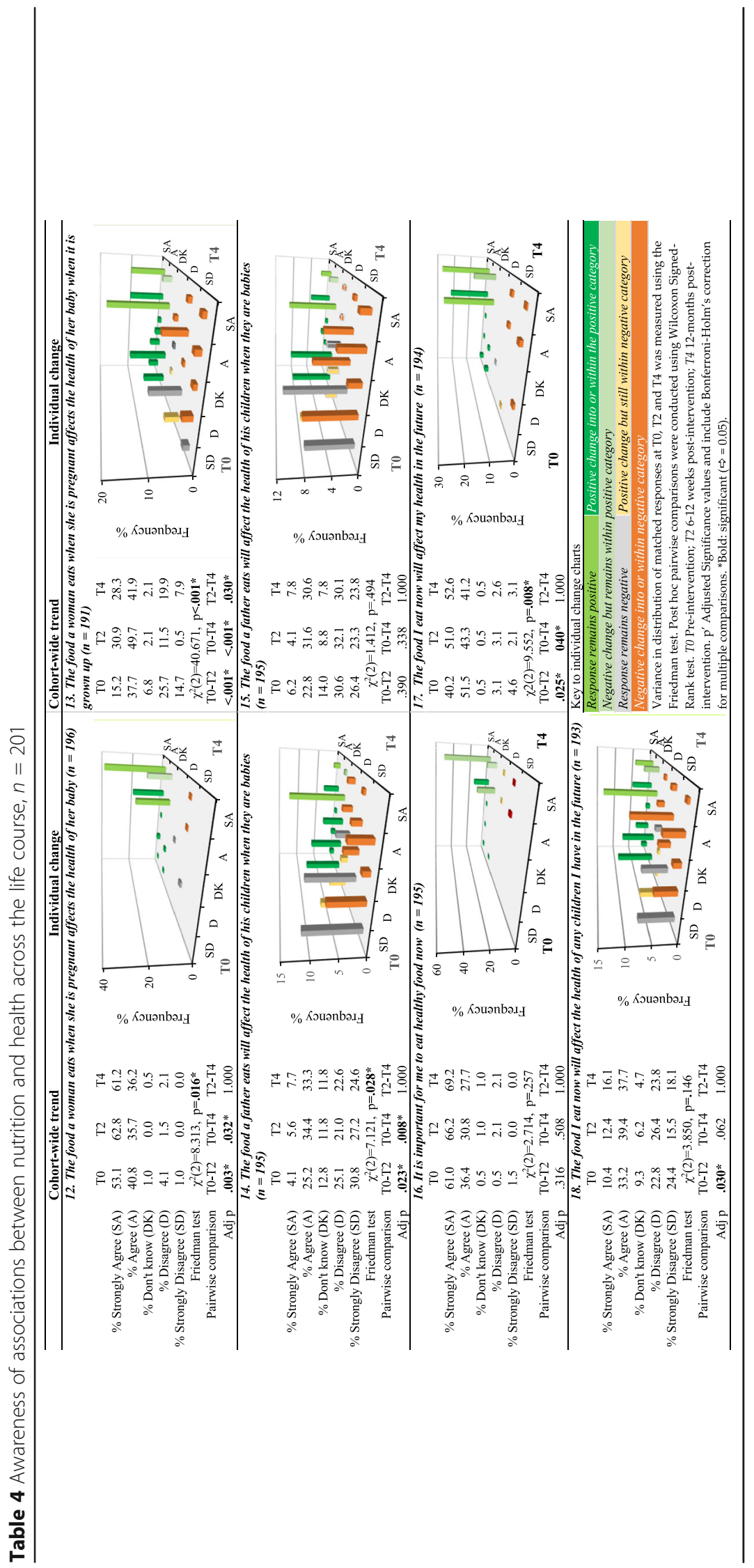


Table 5 Odds ratio $(95 \% \mathrm{Cl})$, awareness of associations between nutrition and health across the life course male compared to female responses

\begin{tabular}{|c|c|c|c|c|c|}
\hline Statement & Time & OR (male cf. female) & $95 \% \mathrm{Cl}$ & $X^{2}(1)$ & $p$ \\
\hline \multirow{3}{*}{$\begin{array}{l}\text { 12.The food a woman eats when she is pregnant affects } \\
\text { the health of her baby }\end{array}$} & T0 & 0.6 & $0.4-1.4$ & 2.908 & .088 \\
\hline & $\mathrm{T} 2$ & 0.7 & $0.4-1.3$ & 1.421 & 699 \\
\hline & T4 & 0.6 & $0.4-1.1$ & 2.421 & .629 \\
\hline \multirow{3}{*}{$\begin{array}{l}\text { 13. The food a woman eats when she is pregnant affects the } \\
\text { health of her baby when it is grown up }\end{array}$} & T0 & 2.2 & $1.3-3.8$ & 8.834 & $.003^{*}$ \\
\hline & $\mathrm{T} 2$ & 1.3 & $0.8-2.3$ & 1.139 & .286 \\
\hline & T4 & 2.2 & $1.3-3.8$ & 8.417 & $.004^{*}$ \\
\hline \multirow{3}{*}{$\begin{array}{l}\text { 14. The food a father eats will affect the health of his children } \\
\text { when they are babies }\end{array}$} & T0 & 3.0 & $1.8-5.2$ & 16.865 & $<.001^{*}$ \\
\hline & $\mathrm{T} 2$ & 2.2 & $1.3-3.7$ & 8.626 & $.003^{*}$ \\
\hline & T4 & 2.9 & $1.7-4.9$ & 14.907 & $<.001^{*}$ \\
\hline \multirow{3}{*}{$\begin{array}{l}\text { 15. The food a father eats will affect the health of his children } \\
\text { when they grow up }\end{array}$} & T0 & 2.6 & $1.6-4.5$ & 12.988 & $<.001^{*}$ \\
\hline & $\mathrm{T} 2$ & 1.8 & $1.1-3.1$ & 5.174 & $.023^{*}$ \\
\hline & T4 & 2.7 & $1.6-4.7$ & 13.797 & $<.001^{*}$ \\
\hline \multirow[t]{3}{*}{ 16. It is important for me to eat healthy food now } & T0 & 0.5 & $0.3-0.8$ & 6.463 & $.011^{*}$ \\
\hline & $\mathrm{T} 2$ & 0.9 & $0.5-1.7$ & 0.061 & .805 \\
\hline & T4 & 0.5 & $0.3-0.9$ & 4.699 & $.030^{*}$ \\
\hline \multirow[t]{3}{*}{ 17. The food I eat now will affect my health in the future } & T0 & 0.8 & $0.4-1.3$ & 0.924 & .337 \\
\hline & $\mathrm{T} 2$ & 0.7 & $0.4-1.2$ & 1.835 & .176 \\
\hline & T4 & 1.1 & $0.6-1.9$ & 0.061 & .805 \\
\hline \multirow{3}{*}{$\begin{array}{l}\text { 18. The food I eat now will affect my health of any children } \\
\text { I have in the future }\end{array}$} & T0 & 2.1 & $1.2-3.5$ & 7.550 & $.006^{*}$ \\
\hline & $\mathrm{T} 2$ & 1.4 & $0.8-2.2$ & 1.517 & .218 \\
\hline & T4 & 1.8 & $1.1-3.1$ & 5.091 & $.024^{*}$ \\
\hline
\end{tabular}

The effect of gender on responses was measured using ordinal logistic regression with proportional odds TO pre-intervention, T2 6-12 weeks post-intervention, T4 12 months post-intervention

*Significant $(a=0.05)$

A small change in awareness was detected in responses to statement 14, suggesting that information sharing without examination of evidence has limited impact. When compared to the significant positive change in awareness of associations between maternal nutritional environment and later life offspring health, this confirms that for students to develop understanding of research evidence, they need to explore data rather than be told of findings.

Most adolescents receive signals from home, school, and community indicating the importance of healthy eating. Therefore, unsurprisingly $61.0 / 36.4 \%$ of students responded SA/A to statement 16 exploring the importance of eating healthy food. While not statistically significant, the change upwards to $69.2 \% / 27.7 \%$ at 12 months post-intervention is promising. Gender-based differences were statistically significant at $\mathrm{T} 0$ and $\mathrm{T} 4$. At $\mathrm{T} 0$, the odds of boys responding positively to this statement were 0.467 that of girls, $p=.011$. Responses of boys shifted markedly at T2, bringing responses in line with those of girls. Girls responses at SA/A level continued to move upwards between T0 (69\%/28.4\%) and T4 (75.2\%/22.2\%). However, boys dropped back to $59.5 \% /$
$36.5 \%$ at $\mathrm{T} 4$, still somewhat higher that their $\mathrm{T} 0$ rates of $50.0 \% / 47.3 \%$. Thus, the odds of boys responding positively at T4 lowered back to 0.507 that of girls, $p=.030$.

Positive (SA/A) responses to statement 17 "The food I eat now will affect my health in the future" were lower than those for statement 16 at T0, 40.2/51.5\%. Postintervention responses shifted significantly upwards and were sustained at 52.6/41.2\% 12 months, $p=.008$.

Statement 18 "The food I eat now will affect the health of any children I have in the future" tested the potential for students to engage with $\mathrm{DOHaD}$ concepts in relation to their potential future offspring. Given their age (11-14 years), this was conceptually challenging as it related to events in their adult future. Responses at T0 were mixed, potentially reflecting this challenge. While overall, there was a positive shift in responses, significant moves occurred in both directions. This suggests that applying these concepts to their future as adults is challenging and should be explored further.

\section{Cognitive engagement and actions}

Recognition of relevance, when followed by action signals investment in learning and is indicative of emotional and cognitive engagement, e.g., 


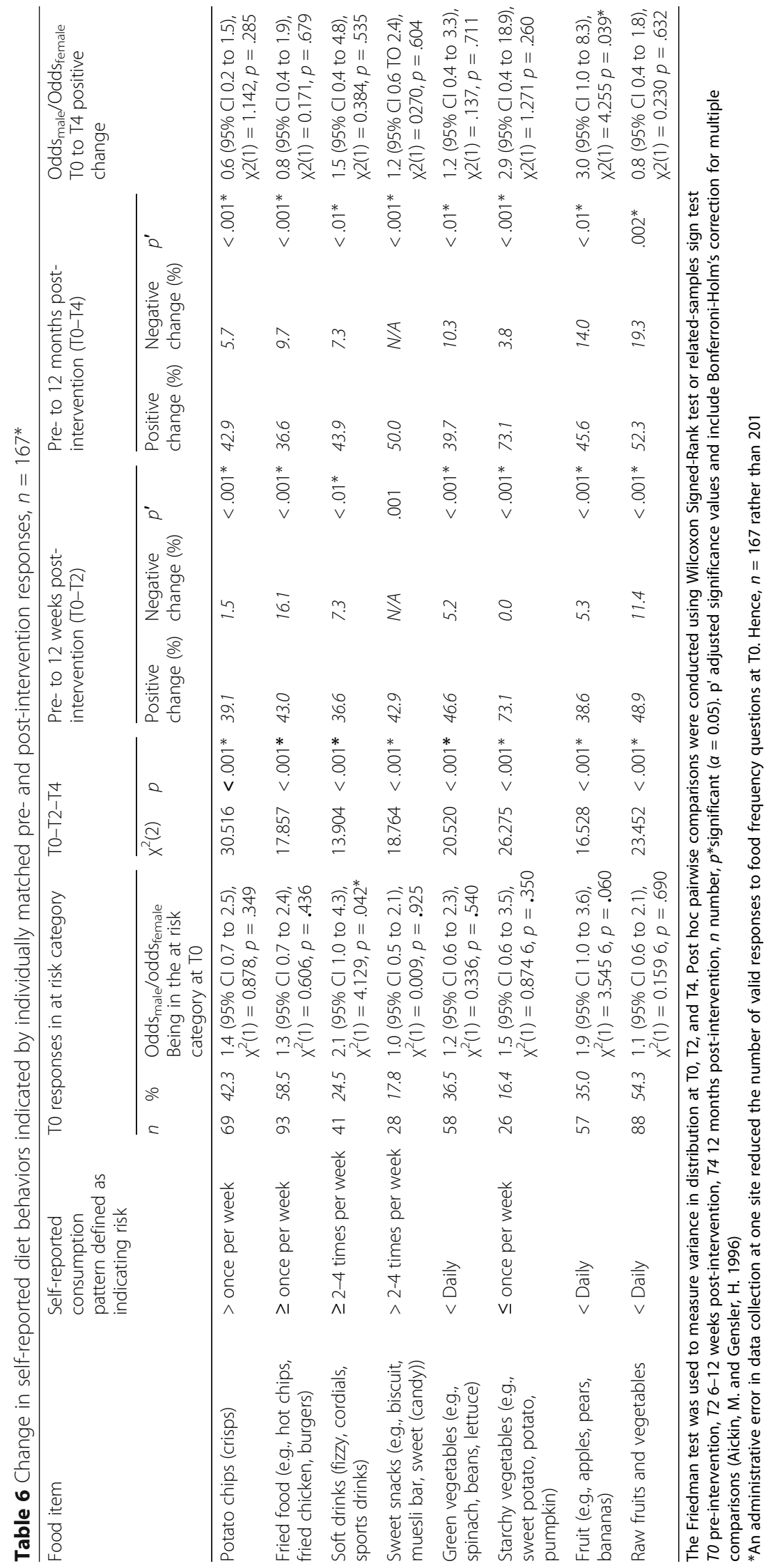




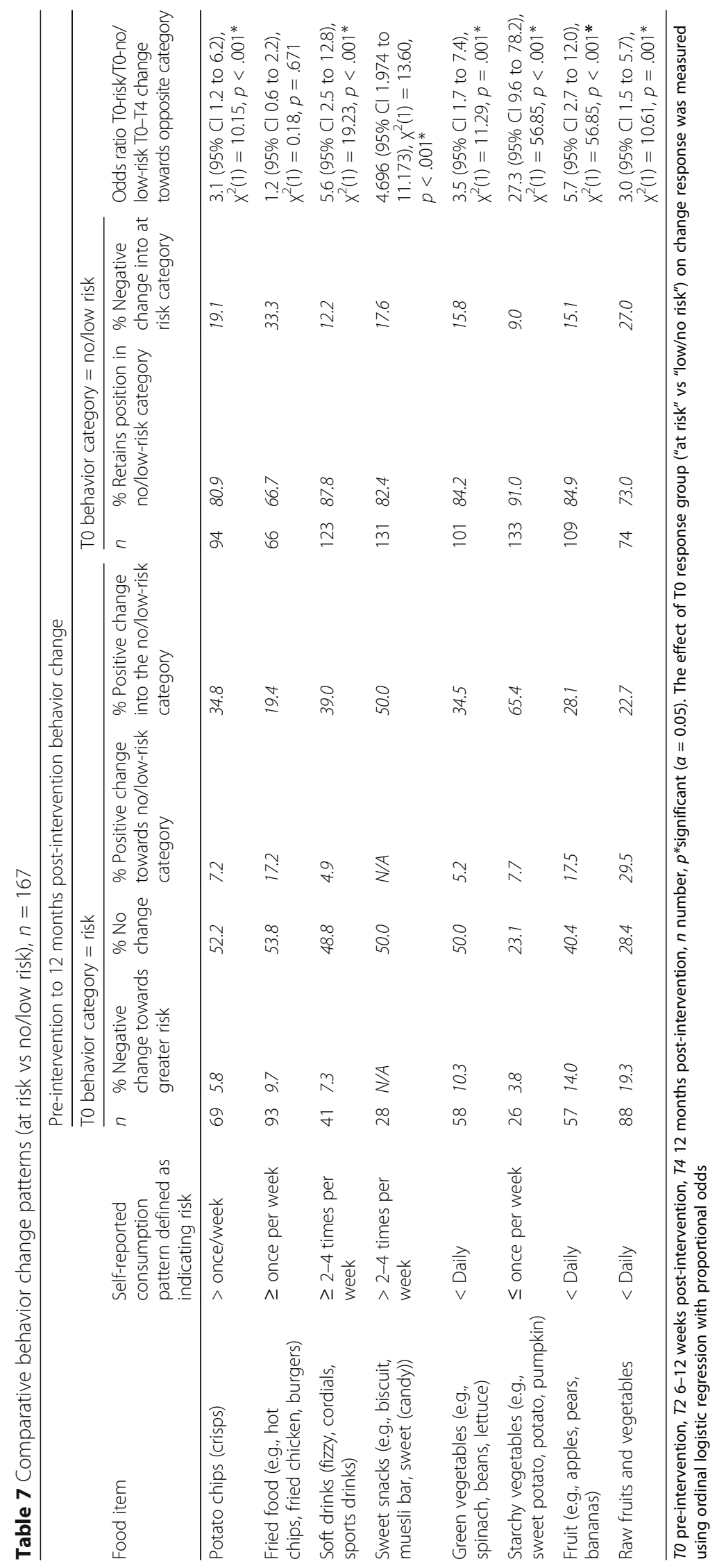




\begin{abstract}
"I had thought about it but I had never really done healthy eating before. Now I pay more attention to healthy eating and exercise. In P.E. I participate more. Like I used to just stand there but now I take part and it is really fun. [Before] I was ashamed, but now I enjoy it and I really take part and I eat healthy too. I eat vegetables." Year 9 female, decile 1-4, 6 months post-intervention
\end{abstract}

The potential of program participation to facilitate nutritional behavior change was assessed using matched selfreported evidence relating to eight key food categories Tables 6 and 7. Not all adolescents need to make nutritional behavior changes. Therefore, we divided the assessment of behavior change into two categories based on the risk-level represented by baseline patterns. We reported at 12 weeks post-intervention indicators of positive change in students whose pre-intervention nutritional behaviors could increase later risk of overweight/obesity and NCD. This was triangulated with interview evidence indicating that change was determined by adolescents in response to evidence they had explored in the HSLEAP programs (Bay et al. 2012a). Matched analysis demonstrates statistically significant sustained change in self-reported behaviors from T0 to T2 and T4 for all food categories for students in the "at risk" group Table 6. Consistent with our reported 12 weeks post-intervention evidence, some negative behavior changes were observed at 12 months postintervention in the group for whom pre-intervention behavior was not in the "at risk" category. However, the odds of positive behavior change for students in the "at risk" group were significantly higher than the odds of students in the "low/no risk" group making negative changes Table 7.

\section{Cognitive engagement and communication}

At T2, increased parental awareness of DOHaDrelated concepts was identified (Bay et al. 2012a) and $73 \%$ of parents responding to a request to comment on the program $(n=55)$ indicated interest in learning about aspects of science explored within the program. Additionally, 37 of the 40 adolescents interviewed at 6 months post-intervention talked about engaging their family in learning from the program and 19 discussed application of their learning in evidence-based actions, examples of which we reported previously (Bay et al. 2012a). These data indicate that students became science communicators in their families. This is a sign of cognitive engagement. In addition to supporting family level behavior change reported in Bay et al. 2012a, this has supported parents to develop an understanding of science as a human endeavor of relevance in their community.
"Back in my day science at school was not so relevant to the children's world. Soana* is telling me about what she is doing. She is really interested and they are looking at how things work. That has changed my mind on what science is so I can see there are branches of it in everyday things and I can see the value of science for her. When I came to the parent's night I was interested and wanting to know more about what Soana* was learning at school and I went away learning something, and I enjoyed the evening. I wanted to come to this meeting because she has been talking about science ever since this program started and she has said that she likes science so I thought well I should come and support her." Parent, decile 14 school; 6 months post-intervention, "name altered

This type of impact is valued by schools as it promotes the worth of science education within communities.

"The value of the program for parents in our community is that they have begun to see what science is a little more. The students are taking back ideas to their families and their communities. We are getting a lot more understanding about how science is impacting the community. We are getting more students wanting to take science - they can see the relevance of $i$. There is a strong link to their lives." HOD science, decile 1-4 school

\section{Discussion}

This study tested the potential of narrative-based science learning contextualized in NCD-related issues to support scientific and health literacy development and facilitate health-promoting actions. Participation was strongly associated with engagement, known to be a prerequisite to the development of capabilities associated with critical citizenship, and associated with higher levels of scientific literacy (Caygill and Sok 2008). Increased understanding of the culture, nature, and process of science as well as research evidence associated with life course understanding of NCD risk was observed. Greater knowledge change was associated with exposure to learning resources enabling students to explore evidence compared to questions relating to evidence not presented in this manner. Assessment of nutritional behavior change demonstrated that the positive change in the at risk group was significantly higher than negative change in the "no/low-risk" group for all but one food item (fried foods). Combined with the significant qualitative evidence from the 6 months post-intervention interview data demonstrating that the observed positive behavior changes were associated with application of evidencebased thinking (Bay et al. 2012a), these data indicate that students in the at risk group made and sustained 
evidence-based decisions in relation to learning associated with the intervention. The high level of communication into the family by students is encouraging as it supports evidence linked to the importance of family engagement in achieving positive adolescent health promotion (Todd et al. 2015).

In some aspects of the evaluation, we identified small increases in understanding and capability development between 3 and 12 months post-intervention, indicative of ongoing development beyond the intervention period. This reflects the notion that each learning module in a program contributes to overarching educative goals. Therefore, ideas explored will be linked into learning beyond the module, supporting ongoing capability development.

The impacts of this study sit in contrast to the questionable value of school-based health interventions expressed in the literature (Khambalia et al. 2012). Unusually for school-based health interventions, experienced science educators embedded in a health-research setting led the intervention design. This enabled a program supportive of educational as well as health/science goals (Bay et al. 2016) and set within a core curriculum area (WHO 2016), addressing issues that connect to the core mission of schools (Waters et al. 2011). Ensuring that the intervention resources supported teachers to develop locally relevant programs addressed issues associated with the impact of school diversity on intervention impacts (Keshavarz Mohammadi et al. 2010).

Evaluation recognized that for education to impact health, assessment must look at whether learning took place before asking whether this learning impacted health. Ideally, the program should also support measurement of long-term health impacts, an issue that we hope to address in the future.

Exploration of health issues in classrooms should be approached with appropriate consideration for pastoral care. The adaptable learning modules used were designed in collaboration with stakeholder schools following 4 years of trials where the context was explored in the Institute classroom with over 5000 students. Care was taken to ensure that negative messages were not presented. While the potential exists for exploration of health-related issues to have negative impacts, and some argue that it is dangerous (Fitzpatrick and Tinning 2014), the overwhelming feedback we received was positive. Anecdotal evidence from teachers during the prestudy developmental period identified that rather than promoting negative responses, the programs created opportunities for positive classroom discussions that challenged individual blame responses to NCD-related health issues that are reflected in social norms and can promote bullying in classrooms.

\section{Limitations}

The study is limited by several factors, including lack of matched control schools. However, strong arguments exist demonstrating the limitation of control studies in complex educational settings (Berliner 2002; Maxwell 2004; Sadler et al. 2016). Factors within the study design addressed internal validity. Individually matched analysis was used throughout the study, addressing issues of individual variance and fixed confounding variables. The use of 30 classrooms across 10 schools contributed to addressing factors associated with heterogeneity in school settings. Biglan et al. argue that time-series studies should be considered as experimental rather than quasiexperimental (Biglan et al. 2000). However, in this study, we were limited to a single pre-intervention baseline where to be considered experimental, the baseline questionnaires should be repeated to determine stability prior to intervention (Biglan et al. 2000). When conducting research in schools, the use of curriculum time for evaluation must be carefully considered. Most New Zealand schools schedule 3 hours per week for science learning within the timetable in years $7-10$. The evaluation processes required 5 hours of this time. The addition of a further hour to collect a second baseline was rejected by participating schools. This was addressed by comparing baseline evidence with known evidence relating to nature of science understanding and nutritional behaviors in New Zealand adolescents. The high level of nature of science understanding at baseline was reflective of international assessment of nature of science understanding in New Zealand 15-year-olds (MoE 2009). Baseline food frequency data was comparative to patterns in the New Zealand National Youth Nutrition Survey (Clinical Trials Research Unit Synovate 2010). Awareness of associations between nutrition in early life and later life health was consistently low across all 10 schools at baseline, measured over a period of 2 years as each school timed the study to suit their own needs. This is parallel to data we have from 900 adults in the Auckland region (Bay et al. 2015), indicating reliability of the baseline. Furthermore, change data was triangulated with interview data from parents and students. Collectively, this indicates that it is highly likely that changes found in individually matched pre-post assessments can be attributed to intervention participation.

Generalizability of findings is likely to be context dependent and associated with opportunity for nature of science exploration within national curricula. The model is designed to be adapted by teachers to fit within the socioecological context of their community and classroom. However, the impact of teacher quality, experience, preparation, and beliefs are known to be significant factors influencing learning outcomes for students (Darling-Hammond et al. 2009; Hattie 2012). 
We have not assessed the impact of teachers on learning outcomes for students. This would be a significant limitation if the study had it been conducted in only one school with few teachers and used set rather than adaptable learning programs. However, the data represents evidence from 30 classrooms in 10 schools where teachers used professional judgment to adapt the program to the context of their community. Further investigation examining outcome variation associated with teacher experience and context would be valuable.

As noted, the study cohort presented limitations in terms of the potential to explore the impact of gender, age, and SES. Gender differences observed should be treated cautiously as we were not able to assess differences in SES and age due to the mid-SES group being from single-sex girls' schools and the year 7-8 cohort being from mid- and high-decile schools only. Further research is underway to address these questions.

\section{Conclusions}

The World Health Organization is promoting the importance of curriculum-embedded school-based partnerships to support primary NCD risk reduction. This study examined whether addressing known shortcomings relating to school-based health promotion, such as shared vision, and understanding of pedagogy and practice could demonstrate the value of combining educative and health goals in support of $\mathrm{DOHaD}$ translation in the adolescent life stage. Our study suggests that the use of a narrative-based pedagogy centered on development of scientific literacy is effective in promoting evidencebased actions by adolescents that are supportive of longterm health. Utilization of mixed methods enabled student, teacher, and parent voices to identify associations between observed knowledge, attitude, and behavior changes and program participation. Strong links to the goals of the national curriculum combined with evidence of positive change in nature of science understanding validated the use of science learning time and offers strong potential for sustainability and future development. Further development and testing of tools and contexts associated with primary NCD risk reduction linked to learning objectives in science, as well as other core learning areas should be explored. Understanding of impacts associated with teacher diversity, student age, gender, and socioecological setting are required, along with assessment of relative sustainability and contextual transferability of scientific literacy capabilities developed in this manner.

\section{Additional files}

Additional file 1: Questionnaires and semi-structured interviews (Student and Parent). This file contains questions used to collect the data presented in the paper. (DOCX $35 \mathrm{~kb}$ )
Additional file 2: Comparison of T0 responses from participants who did not and who did provide T2 and T4 responses. This file contains data comparing the baseline evidence from the group of students who completed all three questionnaires with the group who only completed some questionnaires. (DOCX $26 \mathrm{~kb}$ )

\section{Abbreviations}

DOHaD: Developmental Origins of Health and Disease; HSLEAP: Healthy Start to Life Education for Adolescents Project; NCD: Noncommunicable diseases; SES: Socioeconomic status; T0: Time 0: baseline; T1: Time 1: intervention; T2: Time 2: 3 months post-intervention; T3: Time 3: 6 months postintervention; T4: Time 4: 12 months post-intervention

\section{Acknowledgements}

The study was funded by a grant from Gravida: National Research Centre for Growth and Development. It was made possible by generous contributions of time and expertise from teachers in participating schools that implemented the program and supported the research process. We thank participating students and parents for the time invested in supporting this research. We acknowledge Professor Michael A. Heymann for critical review and thoughtful discussions regarding our work and this manuscript.

\section{Authors' contributions}

$J L B$ conceived and led the study. All authors participated in the design of the study and the development of the study instruments. JLB and HAM led consultation meetings with teaching colleagues across the Auckland region prior to confirmation of the learning and teaching resources. JLB, HAM, DMS, and $\mathrm{MHV}$ provided teacher professional development to support the intervention and participated with schools in learning conferences and/or family meetings associated with the project. HAM led the teaching of the 5hour Liggins Institute component of the program. JLB conducted data analysis and wrote the manuscript. All authors reviewed the manuscript draft and provided feedback. All authors approved the final manuscript.

\section{Ethics approval and consent to participate}

The study was approved by the University of Auckland Human Participants Ethics Committee (ref. 2009/426).

\section{Competing interests}

The authors declare that they have no competing interests.

\section{Publisher's Note}

Springer Nature remains neutral with regard to jurisdictional claims in published maps and institutional affiliations.

\section{Author details}

'Liggins Institute and Gravida, National Centre for Growth and Development, University of Auckland, Auckland, New Zealand. ${ }^{2}$ Departments of Biochemistry and Biomedical Sciences, Obstetrics and Gynecology, and Paediatrics, Farncombe Family Digestive Health Research Institute, McMaster University, Hamilton, Canada. ${ }^{3}$ Centre for Longitudinal Research-He Ara ki Mua, University of Auckland, Auckland, New Zealand. ${ }^{4}$ Liggins Institute, University of Auckland, Private Bag 92109, Victoria Street West, Auckland 1142, New Zealand.

Received: 12 February 2017 Accepted: 7 August 2017

Published online: 06 September 2017

\section{References}

Aickin, M., \& Gensler, H. (1996). Adjusting for multiple testing when reporting research results: the Bonferroni vs Holm methods. American Journal of Public Health, 86(5), 726-728. https://doi.org/10.2105/AJPH.86.5.726.

Alberga, A. S., Sigal, R. J., Goldfield, G., Prud'homme, D., \& Kenny, G. P. (2012). Overweight and obese teenagers: why is adolescence a critical period? Pediatr Obes, 7(4), 261-273.

Bay, J.L, \& Mora, H.A. (2009a). Me, myself, my environment: nutrition, New Zealand Curriculum Level 4. Teacher resource (Trial ed.). Auckland: Liggins Institute. ISBN: 9780473169107. 
Bay, J. L., \& Mora, H. A. (2009b). Me, myself, my environment: growing up, New Zealand Curriculum Level 5. Teacher resource (Trial ed.). Auckland: Liggins Institute. ISBN: 9780473199494

Bay, J. L., Mora, H. A., Sloboda, D. M., Morton, S. M., Vickers, M. H., \& Gluckman, P. D. (2012a). Adolescent understanding of DOHaD concepts: a school-based intervention to support knowledge translation and behaviour change. Journal of Developmental Origins of Health and Disease, 3(6), 469-482.

Bay, J. L., Dewan, C., Cole, K., Pamaka, S., Wagner, B., \& Mora, H. (2012b). Effective school-science partnerships: the LENScience story: facilitating scientific literacy development in New Zealand schools, Auckland: Liggins Institute. Retrieved from http://ebooks.liggins.auckland.ac.nz/the_lenscience_story_2012/. 20 Jan 2017.

Bay, J. L., Sloboda, D. M., Vickers, M. H., \& Mora, H. A. (2012c). Multi-Dimensional Connections. In B. France \& V. Compton (Eds.), Bringing Communities Together: Connecting Learners with Scientists or Technologists (pp. 161-173). Rotterdam: Sense Publishers.

Bay, J., Dixon, R., Morgan. S., Wall, C., Oyamada, M. (2015). Characterising Public Understanding of $\mathrm{DOHaD}$ to Inform Communication Strategies. Journal of Developmental Origins of Health and Disease, 6, Supplement S2.

Bay, J., Morton, S., \& Vickers, M. (2016). Realizing the Potential of Adolescence to Prevent Transgenerational Conditioning of Noncommunicable Disease Risk: Multi-Sectoral Design Frameworks. Healthcare, 4(3), 39. https://doi.org/10. 3390/healthcare4030039.

Bay, J.L., Hipkins, R., Siddiqi, K., Huque, R., Dixon, R., Shirley, D., Tairea, K., Yaqona, D., Mason-Jones, A., Vickers, M.H. (2017). School-based primary NCD risk reduction: Education and public health perspectives. Health Promotion International, 32, 369-379. https://doi.org/10.1093/heapro/daw096.

Bay, J. L., \& Vickers, M. H. (2016). Adolescent education: an opportunity to create a Developmental Origins of Health and Disease (DOHaD) circuit breaker. Journal of Developmentla Origins of Health adn Disease, 7(5), 501-504. https:// doi.org/10.1017/s204017441600026x.

Berliner, D. C. (2002). Comment: Educational research: The hardest science of all. Educational Researcher, 31(8), 18-20.

Biglan, A., Ary, D., \& Wagenaar, A. C. (2000). The value of interrupted time-series experiments for community intervention research. Prevention Science, 1(1), 31-49.

Bloom, D. E., Cafiero, E. T., Jané-Llopis, E., Abrahams-Gessel, S., Bloom, L. R., Fathhima, S., et al. (2011). The global economic burden of noncommunicable diseases. Geneva: World Economic Forum.

Bolstad, R., \& Bull, A. (2013). Strengthening engagements between schools and the science community: Final report. NZCER Press, Wellington, New Zealand.

Boyatzis, R. E. (1998). Transforming qualitative information: thematic analysis and code development: Thousand Oaks: Sage Publications.

Bryman, A. (2008). Why do researchers integrate/combine/mesh/blend/mix/merge/ fuse quantitative and qualitative research? London: SAGE Publications Ltd..

Caygill, R., \& Sok, S. (2008). PISA 2006: School context of science achievement. Wellington: New Zealand Ministry of Education.

Chestnov, O., Hilten, M. V., Mclff, C., \& Kulikov, A. (2013). Rallying United Nations organizations in the fight against noncommunicable diseases. Bulletin of the World Health Organization, 91, 623-623A.

Clinical Trials Research Unit Synovate. (2010). A national survey of children and young people's physical activity and dietary behaviours in New Zealand: 2008/ 09--key findings. Wellington: Ministry of Health http://www.health.govt.nz/ publication/national-survey-children-and-young-peoples-physical-activity-anddietary-behaviours-new-zealand-2008. Accessed 20 Jan 2017.

Coppell, K. J., Mann, J. I., Williams, S. M., Jo, E., Drury, P. L., Miller, J. C., \& Parnell, W. R. (2013). Prevalence of diagnosed and undiagnosed diabetes and prediabetes in New Zealand: Findings from the 2008/09 Adult Nutrition Survey. The New Zealand Medical Journal (Online), 126 (1370), 23-42.

Craigie, A. M., Lake, A. A., Kelly, S. A., Adamson, A. J., \& Mathers, J. C. (2011). Tracking of obesity-related behaviours from childhood to adulthood: a systematic review. Maturitas, 70(3), 266-284.

Darling-Hammond, L., Wei, R. C., Andree, A., Richardson, N., \& Orphanos, S. (2009). Professional learning in the learning profession. Washington, DC: National Staff Development Council.

Engdahl, E., \& Lidskog, R. (2014). Risk, communication and trust: Towards an emotional understanding of trust. Public Understanding of Science, 23(6), 703717. https://doi.org/10.1177/0963662512460953.

Fitzpatrick, K., \& Tinning, R. (2014). Health education's fascist tendencies: A cautionary exposition. Critical Public Health, 24(2), 132-142.
Grace, M., \& Bay, J. (2011). Developing a pedagogy to support science for health literacy. Asia-Pacific Forum on Science Learning and Teaching,12(2), 1-13.

Hanson, M. A., \& Gluckman, P. D. (2014). Early developmental conditioning of later health and disease: Physiology or pathophysiology? Physiological Reviews, 94(4), 1027-1076.

Hattie, J., 2012. Visible learning for teachers: maximizing impact on learning. London: Routledge.

Hipkins, R., Bolstad, R., Boyd, S., \& McDowall, S. (2014). Key competencies for the future. New Zealand: NZCER Press.

Hodson, D. (2011). Looking to the future: Building a curriculum for social action Rotterdam: SENSE Publishers.

IBM Corp. (2015). IBM SPSS statistics for Macintosh, version 23.0. Armonk: IBM Corp.

Jefferies, C., Carter, P., Reed, P. W., Cutfield, W., Mouat, F., Hofman, P. L., \& Gunn, A J. (2012). The incidence, clinical features, and treatment of type 2 diabetes in children $<15 \mathrm{yr}$ in a population-based cohort from Auckland, New Zealand, 1995-2007. Pediatric Diabetes, 13(4), 294-300. https://doi.org/10.1111/j.13995448.2011.00851.x

Kahana, O., \& Tal, T. (2014). Understanding of high-achieving science students on the nature of science. International Journal of STEM Education, 1(1), 13. https://doi.org/10.1186/s40594-014-0013-5.

Keshavarz Mohammadi, N., Rowling, L., \& Nutbeam, D. (2010). Acknowledging educational perspectives on health promoting schools. Health Education, 110(4), 240-251.

Khambalia, A. Z., Dickinson, S., Hardy, L. L., Gill, T., \& Baur, L. A. (2012). A synthesis of existing systematic reviews and meta-analyses of school-based behavioural interventions for controlling and preventing obesity. Obesity Reviews, 13(3), 214-233.

Lederman, N. G., Lederman, J. S., \& Antink, A. (2013). Nature of science and scientific inquiry as contexts for the learning of science and achievement of scientific literacy. International Journal of Education in Mathematics, Science and Technology, 1(3), 137-147. http://ijemst.com/issues/1_3_1_Lederman_ Lederman_Antink.pdf.

"LENScience Face-to-Face" n.d. http://www.lenscience.auckland.ac.nz/en/about/ programmes/face-to-face.html. Accessed 20 Jan 2017.

"LENScience HSLEAP, LENScience Healthy Start to Life Education for Adolescents Project", n.d. http://www.lenscience.auckland.ac.nz/en/about/teaching-andlearning-resources/HSLeaP.html. Accessed 20 Jan 2017.

Levers, M.-J. D. (2013). Philosophical paradigms, grounded theory, and perspectives on emergence. SAGE Open, 3(4). https://doi.org/10.1177/ 2158244013517243.

Maxwell, J. A. (2004). Causal explanation, qualitative research, and scientific inquiry in education. Educational Researcher, 33(2), 3-11.

Ministry of Education. (2017). School Deciles. https://education.govt.nz/school/ running-aschool/resourcing/operational-funding/school-decile-ratings/. Accessed 15 Aug 2017.

MoE, Ministry of Education. (2007). The New Zealand curriculum for Englishmedium teaching and learning in years 1-13. Wellington: Learning Media Ltd http://nzcurriculum.tki.org.nz/. Accessed 20 Jan 2017.

MoE, Ministry of Education (2009). Education counts | PISA 2009. www. educationcounts.govt.nz/topics/research/pisa/pisa_2009. Accessed 20 Jan 2017.

MoE, Ministry of Education (2012); Education counts: directories, New Zealand schools. http://www.educationcounts.govt.nz/directories/list-of-nz-schools. Accessed Dec 2012.

MoH, Ministry of Health. (2012). The health of New Zealand adults 2011/12: key findings of the New Zealand health survey. Wellington, New Zealand. www. health.govt.nz/publication/health-new-zealand-adults-2011-12. Accessed 20 Jan 2017.

Ng, S. F., Lin, R. C., Laybutt, D. R., Barres, R., Owens, J. A., \& Morris, M. J. (2010). Chronic high-fat diet in fathers programs beta-cell dysfunction in female rat offspring. Nature, 467(7318), 963-966. https://doi.org/10.1038/nature09491.

Nutbeam, D. (2008). The evolving concept of health literacy. Social Science \& Medicine, 67(12), 2072-2078.

Punch, K. F. (2009). Introduction to research methods in education. Los Angeles: Sage.

Rajput, N., Tuohy, P., Mishra, S., Smith, A., \& Taylor, B. (2015). Overweight and obesity in 4-5-year-old children in New Zealand: Results from the first 4 years (2009-2012) of the B4School check programme. Journal of Paediatrics and Child Health, 51(3), 334-343. https://doi.org/10.1111/jpc.12716.

Retzbach, J., Otto, L., \& Maier, M. (2016). Measuring the perceived uncertainty of scientific evidence and its relationship to engagement with science. Public 
Understanding of Science, 25(6), 638-655. https://doi.org/10.1177/ 0963662515575253.

Rychen, D. S., \& Salganik, L. H. (Eds.). (2003). Key competencies for a successful life and well-functioning society. Cambridge: Hogrefe Publishing.

Sadler, T. D., Chambers, F. W., \& Zeidler, D. L. (2004). Student conceptualizations of the nature of science in response to a socioscientific issue. International Journal of Science Education, 26(4), 387-409. https://doi.org/10.1080/ 0950069032000119456

Sadler, T. D., Romine, W. L., \& Topçu, M. S. (2016). Learning science content through socio-scientific issues-based instruction: A multi-level assessment study. International Journal of Science Education, 38(10), 1622-1635.

Steinberg, L. (2005). Cognitive and affective development in adolescence. Trends in Cognitive Sciences, 9(2), 69-74.

Todd, A. S., Street, S. J., Ziviani, J., Byrne, N. M., \& Hills, A. P. (2015). Overweight and obese adolescent girls: the importance of promoting sensible eating and activity behaviors from the start of the adolescent period. International Journal of Environmental Research and Public Health, 12(2), 2306-2329

Utter, J., Denny, S., Teevale, T., Peiris-John, R., \& Dyson, B. (2015). Prevalence and recent trends in overweight, obesity, and severe obesity among New Zealand adolescents. Childhood Obesity, 11(5), 585-589. https://doi.org/10. 1089/chi.2014.0151

Waters, E., de Silva-Sanigorski, A., Hall, B. J., Brown, T., Campbell, K. J., Gao, Y., et al, (2011). Interventions for preventing obesity in children. Cochrane Database of Systematic Reviews, 12, CD001781.

WHO, World Health Organization. (2015). Global status report on noncommunicable diseases 2014. Geneva: World Health Organization Retreived from apps.who.int/iris/bitstream/10665/148114/1/9789241564854_ eng.pdf?ua=1 January 20, 2017.

WHO, World Health Organization. (2016). Report of the commission on ending childhood obesity. Geneva: World Health Organization Retreived from www. who.int/end-childhood-obesity/en/. 20 Jan 2017.

\section{Submit your manuscript to a SpringerOpen ${ }^{\odot}$ journal and benefit from:}

- Convenient online submission

Rigorous peer review

- Open access: articles freely available online

- High visibility within the field

- Retaining the copyright to your article

Submit your next manuscript at $\gg$ springeropen.com 